\title{
Differences in dietary intakes, food sources and determinants of total flavonoids between Mediterranean and non-Mediterranean countries participating in the European Prospective Investigation into Cancer and Nutrition (EPIC) study
}

Raul Zamora-Ros ${ }^{1 *}$, Viktoria Knaze ${ }^{2}$, Leila Luján-Barroso ${ }^{1}$, Isabelle Romieu ${ }^{2}$, Augustin Scalbert ${ }^{2}$, Nadia Slimani ${ }^{2}$, Anette Hjartåker ${ }^{3}$, Dagrun Engeset ${ }^{4}$, Guri Skeie ${ }^{4}$, Kim Overvad ${ }^{5}$, Lea Bredsdorff ${ }^{6}$, Anne Tjønneland ${ }^{7}$, Jytte Halkjær ${ }^{7}$, Timothy J. Key ${ }^{8}$, Kay-Tee Khaw ${ }^{9}$, Angela A. Mulligan?, Anna Winkvist ${ }^{10}$, Ingegerd Johansson ${ }^{11}$, H. Bas Bueno-de-Mesquita ${ }^{12,13}$, Petra H. M. Peeters ${ }^{14,15}$, Peter Wallström ${ }^{16}$, Ulrika Ericson ${ }^{17}$, Valeria Pala ${ }^{18}$, Maria Santucci de Magistris ${ }^{19}$, Silvia Polidoro ${ }^{20}$, Rosario Tumino $^{21}$, Antonia Trichopoulou ${ }^{22,23}$, Vardis Dilis ${ }^{23}$, Michael Katsoulis ${ }^{23}$,

José María Huerta ${ }^{24,25}$, Virginia Martínez ${ }^{26}$, María-José Sánchez ${ }^{25,27}$, Eva Ardanaz ${ }^{25,28}$, Pilar Amiano ${ }^{25,29}$, Birgit Teucher ${ }^{30}$, Verena Grote ${ }^{30}$, Benedetta Bendinelli ${ }^{31}$, Heiner Boeing ${ }^{32}$, Jana Förster ${ }^{32}$,

Marina Touillaud ${ }^{33}$, Florence Perquier ${ }^{33}$, Guy Fagherazzi ${ }^{33}$, Valentina Gallo ${ }^{15,34}$, Elio Riboli ${ }^{15}$ and Carlos A. González ${ }^{1}$

${ }^{1}$ Unit of Nutrition, Environment and Cancer, Cancer Epidemiology Research Programme, Catalan Institute of Oncology (ICO-IDIBELL), Avda Gran Via 199-203, 08907 L'Hospitalet de Llobregat, Barcelona, Spain

${ }^{2}$ Section of Nutrition and Metabolism, International Agency for Research on Cancer (IARC), Lyon, France

${ }^{3}$ Department of Nutrition, Institute of Basic Medical Sciences, University of Oslo, Oslo, Norway

${ }^{4}$ Department of Community Medicine, University of Tromsø, Tromsø, Norway

${ }^{5}$ Section of Epidemiology, Department of Public Health, Aarbus University, Aarbus, Denmark

${ }^{6}$ National Food Institute, Technical University of Denmark, Moerkhoej, Denmark

${ }^{7}$ Danish Cancer Society Research Center, Copenhagen, Denmark

${ }^{8}$ Cancer Epidemiology Unit, University of Oxford, Oxford, UK

${ }^{9}$ Department of Public Health and Primary Care, University of Cambridge, Cambridge, UK

${ }^{10}$ Department of Internal Medicine and Clinical Nutrition, Sablgrenska Academy, University of Gothenburg,

Gothenburg, Sweden

${ }^{11}$ Department of Odontology, Cariology, Umeå University, Umeå, Sweden

${ }^{12}$ National Institute for Public Health and the Environment (RIVM), Bilthoven, The Netherlands

${ }^{13}$ Department of Gastroenterology and Hepatology, University Medical Center Utrecht, Utrecht, The Netherlands

${ }^{14}$ Julius Center for Health Sciences and Primary Care, University Medical Center Utrecht, Utrecht, The Netherlands

${ }^{15}$ Department of Epidemiology and Biostatistics, School of Public Health, Faculty of Medicine, Imperial College, London, UK

${ }^{16}$ Nutrition Epidemiology Research Group, Department of Clinical Sciences, Lund University, Malmö, Sweden

${ }^{17}$ Diabetes and Cardiovascular Disease, Genetic Epidemiology, Department of Clinical Sciences, Lund University,

Malmö, Sweden

${ }^{18}$ Nutritional Epidemiology Unit, Fondazione IRCCS Istituto Nazionale dei Tumori, Milan, Italy

${ }^{19}$ Department of Clinical and Experimental Medicine, Federico II University, Naples, Italy

${ }^{20}$ Human Genetic Foundation (HuGeF), Torino, Italy

${ }^{21}$ Cancer Registry and Histopathology Unit, 'Civile M.P. Arezzo' Hospital, Ragusa, Italy

${ }^{22}$ WHO Collaborating Center for Food and Nutrition Policies, Department of Hygiene, Epidemiology and Medical Statistics, University of Athens Medical School, Athens, Greece

${ }^{23}$ Hellenic Health Foundation, Athens, Greece

Abbreviations: 24-HDR, $24 \mathrm{~h}$ dietary recall; EPIC, European Prospective Investigation into Cancer and Nutrition; FCDB, food composition database; MED, Mediterranean; PA, proanthocyanidins.

*Corresponding author: Dr R. Zamora-Ros, fax +34 932607787, email rzamora@iconcologia.net 
${ }^{24}$ Department of Epidemiology, Murcia Regional Health Council, Spain

${ }^{25}$ CIBER Epidemiología y Salud Pública (CIBERESP), Barcelona, Spain

${ }^{26}$ Public Health Directorate, Asturias, Spain

${ }^{27}$ Andalusian School of Public Health, Granada, Spain

${ }^{28}$ Navarre Public Health Institute, Pamplona, Spain

${ }^{29}$ Public Health Division of Gipuzkoa, BIODonostia Research Institute, Department of Health of the Regional Government of the Basque Country, San Sebastian, Spain

${ }^{30}$ Department of Cancer Epidemiology, German Cancer Research Center, Heidelberg, Germany

${ }^{31}$ Molecular and Nutritional Epidemiology Unit, Cancer Research and Prevention Institute-ISPO, Florence, Italy

${ }^{32}$ Department of Epidemiology, German Institute of Human Nutrition Potsdam Rehbrücke, Nuthetal, Germany

${ }^{33}$ INSERM U1O18, Center for Research in Epidemiology and Population Health (CESP), Villejuif, France

${ }^{34}$ Department of Social and Environmental Health Research, London School of Hygiene and Tropical Medicine, London, UK

(Submitted 23 February 2012 - Final revision received 19 June 2012 - Accepted 25 June 2012 - First published online 14 September 2012)

\section{Abstract}

A greater adherence to the traditional Mediterranean (MED) diet is associated with a reduced risk of developing chronic diseases. This dietary pattern is based on higher consumption of plant products that are rich in flavonoids. We compared the total flavonoid dietary intakes, their food sources and various lifestyle factors between MED and non-MED countries participating in the EPIC study. Flavonoid intakes and their food sources for 35628 subjects, aged 35-74 years and recruited between 1992 and 2000, in twenty-six study centres were estimated using standardised $24 \mathrm{~h}$ dietary recall software (EPIC-Soft ${ }^{\circledR}$ ). An ad hoc food composition database on flavonoids was compiled using analytical data from the United States Department of Agriculture and Phenol-Explorer databases. Moreover, it was expanded to include using recipes, estimations of missing values and flavonoid retention factors. No significant differences in total flavonoid mean intake between non-MED countries $(373.7 \mathrm{mg} / \mathrm{d})$ and MED countries $(370.2 \mathrm{mg} / \mathrm{d})$ were observed. In the non-MED region, the main contributors were proanthocyanidins ( $48.2 \%)$ and flavan-3-ol monomers (24.9\%) and the principal food sources were tea (25.7\%) and fruits (32.8\%). In the MED region, proanthocyanidins (59.0\%) were by far the most abundant contributor and fruits $(55 \cdot 1 \%)$, wines $(16 \cdot 7 \%)$ and tea $(6.8 \%)$ were the main food sources. The present study shows similar results for total dietary flavonoid intakes, but significant differences in flavonoid class intakes, food sources and some characteristics between MED and non-MED countries. These differences should be considered in studies about the relationships between flavonoid intake and chronic diseases.

\section{Key words: Flavonoids: Intake: Sources: Phenolics: European Prospective Investigation into Cancer and Nutrition}

A Mediterranean (MED) diet is the traditional dietary pattern observed in countries bordering the Mediterranean Sea. It is characterised by a high consumption of fruits, vegetables, unrefined cereals, legumes, nuts and seeds, olive oil, a moderate wine consumption and lower intake of animal products. The MED diet was proposed as a healthy dietary pattern based on the evidence of its protective role in some chronic diseases $^{(1-5)}$. As these plant-based products are high in flavonoids $^{(6,7)}$, a possible link between flavonoids and reported health benefits may be considered.

Flavonoids constitute a wide group of secondary plant metabolites that are ubiquitously distributed in the plant kingdom. Flavonoids are polyphenolic compounds possessing fifteen carbons, with two aromatic rings (rings $\mathrm{A}$ and $\mathrm{B}$ ) joined by a linear three-carbon chain usually forming a closed pyran ring (ring C). According to the modifications of the central C-ring, they are often divided into six classes: anthocyanidins, flavonols, flavanones, flavones, isoflavones and flavanols or flavan-3-ols, including monomers, proanthocyanidins (PA) (oligomers and polymers of flavan-3-ol monomers) and flavanol-derived compounds (theaflavins and thearubigins) ${ }^{(8)}$.

Despite their low-to-moderate bioavailability, high interand intra-individual variation in absorption and rapid conjugation $^{(9)}$, flavonoids have been extensively studied in the last two decades due to their potential health effects, such as antioxidant, anti-inflammatory, anticarcinogenic, anti-obesity, anti-allergic and anti-diabetic properties ${ }^{(10,11)}$. Associations between the consumption of total or classes of flavonoids and chronic disease prevention have also been suggested in several case-control and a few cohort studies $^{(12,13)}$. Epidemiological evidence of the role of flavonoid intake against the risk of some chronic diseases is promising, but not conclusive. Complete descriptive studies of dietary intake are the first step in the assessment of the potential relationship between flavonoids and health.

To date, total flavonoid intake has been estimated in a few descriptive studies (Table 1) ${ }^{(14-24)}$. Moreover, these results varied widely among the studies because of differences in the flavonoid classes included, food composition tables used and dietary assessment methodologies utilised. It is difficult, therefore, to compare the existing data, and the present total dietary flavonoid estimations do not yet allow us to conclude which countries, i.e., MED or non-MED countries, consume more flavonoids. Hence, the present study aimed to estimate total flavonoid intake among European adults from MED and non-MED countries participating in the European 
Table 1. Estimated flavonoid intake in adults in several countries

\begin{tabular}{|c|c|c|c|c|c|c|c|c|c|c|c|}
\hline Study & Year & Country & Population & $\begin{array}{c}\text { Dietary } \\
\text { assessment }\end{array}$ & FCDB & $\begin{array}{c}\text { Flavonoid } \\
\text { without PA } \\
\text { intake }(\mathrm{mg} / \mathrm{d})\end{array}$ & $\begin{array}{c}\text { PA } \\
\text { intake } \\
\text { (mg/d) }\end{array}$ & $\begin{array}{l}\text { Total } \\
\text { flavonoid } \\
\text { intake } \\
(\mathrm{mg} / \mathrm{d})\end{array}$ & $\begin{array}{l}\text { Major class } \\
\text { contributor }\end{array}$ & $\begin{array}{l}\text { Main food } \\
\text { sources }\end{array}$ & Reference \\
\hline SUVIMAX & 1994 & France & 4942 & Dietary history & $\begin{array}{l}\text { Phenol } \\
\text { explorer* }\end{array}$ & 201 & 227 & 428 & PA (53\%) & Fruits, wine, tea & (20) \\
\hline $\begin{array}{l}\text { Stomach cancer } \\
\text { case-control }\end{array}$ & $1997-2007$ & Italy & 777 & FFQ & USDA† & $127 \ddagger$ & 291 & 417 & PA (70\%) & Fruits, wine, tea & (17) \\
\hline EPIC & $1992-2000$ & Spain & 40683 & Dietary history & USDA§ & $124 \ddagger$ & 189 & 313 & PA (60\%) & Fruits, wine & (19) \\
\hline NHANES & 1999-2002 & USA & 8809 & 24-HDR & USDA† & $190 \ddagger$ & 95 & 285 & Flavan-3-ols (64\%) & $\begin{array}{l}\text { Tea, citrus fruit } \\
\text { juices, fruits }\end{array}$ & $(14,15)$ \\
\hline FINDIET & 2002 & Finland & 2007 & 48-HDR & Finnish FCDB & $93 \|$ & 116 & 209 & PA (50\%) & $\begin{array}{l}\text { Fruits, tea, } \\
\text { chocolate }\end{array}$ & (16) \\
\hline EPIC & $1994-1999$ & Greece & 28572 & FFQ & USDA§ & $86 \ddagger$ & 75 & 161 & PA (47\%) & Fruits, wine, tea & (18) \\
\hline $\begin{array}{l}\text { National } \\
\text { Nutrition } \\
\text { Survey }\end{array}$ & 1995 & Australia & 17326 & 24-HDR & USDA† & $454 \ddagger$ & & & Flavan-3-ols (93\%) & Tea, fruits & $(21) q$ \\
\hline $\begin{array}{l}\text { Dutch National } \\
\text { Food } \\
\text { Consumption } \\
\text { Survey }\end{array}$ & 1985 & The Netherlands & 10312 & Dietary history & USDA† & $211 \ddagger$ & & & Flavan-3-ols (69\%) & Tea, fruits & $(23,24) q$ * * \\
\hline $\begin{array}{l}\text { Danish } \\
\text { Household } \\
\text { Consumption } \\
\text { Survey }\end{array}$ & 1987 & Denmark & & Dietary history & USDA† & $175 \ddagger$ & & & Flavan-3-ols (85\%) & Tea, fruits & (22) $\boldsymbol{q}^{\star *}$ \\
\hline
\end{tabular}

FCDB, food composition database; PA, proanthocyanidins; SUVIMAX, SUpplémentation en VItamines et Minéraux Anti-oXydants Study; USDA, United States Department of Agriculture; EPIC, European Prospective Investigation into Cancer and Nutrition; NHANES, National Health and Nutrition Examination Survey; 24-HDR, 24h dietary recall; FINDIET, National Finnish Diet Study; 48-HDR, $48 \mathrm{~h}$ dietary recall.

*Database with dihydroflavonols which were included in total flavonoid intake presented in this table.

† USDA database on flavonoids, version 1, March 2003.

¥ Thearubigins were included in total flavonoid intake presented in this table.

§USDA database on flavonoids, version 2.1, January 2007.

|| Theaflavins and thearubigins were not included in total flavonoid intake presented in this table.

I Calculated taking into account flavonoid intake without PA, because PA intake was not available at the time the study was done.

${ }^{* *}$ Recalculated using USDA databases by Johannot \& Somerset ${ }^{211}$. 
Prospective Investigation into Cancer and Nutrition (EPIC) study. Furthermore, the present study also aimed to assess the main flavonoid food sources and lifestyle characteristics that could partly explain the flavonoid intake variability among these countries.

\section{Materials and methods}

\section{Study population}

The EPIC study is an ongoing prospective cohort study conducted in twenty-three centres throughout ten European countries to investigate the role of nutrition, lifestyle, biomarkers and genetic factors in the aetiology of cancer and other chronic diseases ${ }^{(25,26)}$. A total of 521448 subjects (29.4\% men), aged 21-83 years, were enrolled between 1992 and 2000. Most of the participants were recruited from the general population within defined geographical areas, with some exceptions: women who were members of a health insurance programme for state school employees (France), women attending breast cancer screening (Utrecht, the Netherlands and Florence, Italy), blood donors (some centres in Italy and Spain) and vegetarians (the 'health conscious' cohort in Oxford, UK). For the purpose of dietary analyses, the twenty-three administrative EPIC centres were redefined into twenty-seven geographical areas ${ }^{(27)}$. A total of nineteen of the twenty-seven redefined EPIC centres had both male and female participants, and eight recruited only women (France; Norway; Utrecht, The Netherlands; and Naples, Italy).

Dietary data used in the present paper were obtained from the EPIC calibration study, in which a $24 \mathrm{~h}$ dietary recall (24-HDR) was administered to a stratified random sample of approximately 8\% (36994 subjects) of the entire EPIC cohort ${ }^{(27)}$. A total of 35628 subjects with 24-HDR data from twenty-six centres were included in the present analysis, after exclusion of sixteen subjects due to missing baseline FFQ data, 941 subjects aged less than 35 years or over 74 years (because these age groups had low representation) and all participants from the health conscious group (409 subjects), because vegetarians and vegans consume a very different diet from the rest of the cohort ${ }^{(28)}$. The present study was conducted according to the guidelines laid down in the Declaration of Helsinki, and all procedures involving human subjects were approved by ethical review boards from the International Agency for Research on Cancer (IARC) and all local participating centres approved the study. Written informed consent was obtained from all subjects.

\section{Dietary and lifestyle information}

Dietary information was obtained through a single standardised 24-HDR interview using computerised software (EPICSoft ${ }^{\circledR}$; International Agency for Research on Cancer) ${ }^{(29,30)}$, which was administered face-to-face in all centres, except in Norway, where it was done by telephonic interview ${ }^{(31)}$. In the EPIC study, about 2000 aggregated food items were reported per country in the 24-HDR, of which approximately forty food items were not present in our food composition database (FCDB). Most of these food items, except coffee substitutes and cola drinks, do not contain flavonoids in their composition (such as water, sugar, margarine, caramel, white chocolate, tonic soft drink, chewing gum, artificial sweetener, salt and gelatine) or they are infrequently consumed in the EPIC population (such as bamboo sprouts, carambola, pumpkin flower, orgeat, rose hips, physalis and vanilla). Data on other lifestyle factors, including education, anthropometry, physical activity (combining both occupation, household and leisure time activities) and smoking history, were collected at baseline through standardised questionnaires and have been described elsewhere ${ }^{(26,27,32)}$. Data on age, as well as on body weight and height, were mostly self-reported by the participants during the 24-HDR interview. The mean time interval between these baseline measures and the 24HDR interview varied by country, from $1 \mathrm{~d}$ to 3 years later ${ }^{(27)}$

\section{Flavonoid Food Composition Database}

Our FCDB gathered composition data on six flavonoid classes: anthocyanidins (cyanidin, delphinidin, malvidin, pelargonidin, peonidin and petunidin), flavanols (flavan-3-ol monomers (catechin, epigallocatechin, epicatechin, epicatechin-3-gallate, epigallocatechin-3-gallate, gallocatechin and catechin-3-gallate), PA (dimers, trimers, 4-6-mers, 7-10-mers and >10-mers) and theaflavins (theaflavin, theaflavin- $3,3^{\prime}$-digallate, theaflavin-3'-gallate and theaflavin-3-gallate)), flavonols (isorhamnetin, kaempferol, myricetin and quercetin), flavones (apigenin and luteolin), flavanones (eriodictyol, hesperetin and naringenin) and isoflavones (daidzein, genistein, glycetin, biochanin $\mathrm{A}$, formononetin and equol) ${ }^{(33-36)}$. Thearubigins were not included in the present study because they were obtained by a non-specific spectrophotometric method ${ }^{(7)}$.

Flavonoid data were mainly obtained from the United States Department of Agriculture FCDB on flavonoids (version 2.1 released in 2007, although more recently a new version has been developed in 2011) $)^{(7)}$, isoflavones (updated in 2008) ${ }^{(37)}$ and PA (released in 2004) ${ }^{(38)}$, and the Phenol-Explorer FCDB (developed in 2009) ${ }^{(6)}$ and the UK Food Standards Agency FCDB on isoflavones (released in 2010) ${ }^{(39)}$. The United States Department of Agriculture and Phenol-Explorer FCDB contain flavonoid data from a systematic and comprehensive collection of worldwide analytical data. Furthermore, our flavonoid FCDB was expanded by using retention factors, calculating flavonoid content of recipes, estimating missing values based on similar foods (by botanical family and plant part), obtaining consumption data for food group items and employing botanical data for logical zeros. The retention factors applied to all flavonoid classes, except isoflavones, were $0.70,0.35$ and 0.25 after frying, cooking in a microwave oven and boiling, respectively ${ }^{(40)}$. These retention factors were not applied to isoflavones, because their cooking losses are usually minimal ${ }^{(41)}$. The final FCDB on flavonoids contained 1877 food items and $10 \%$ of these food items had missing values. 


\section{Statistical analyses}

Dietary flavonoid values were calculated using generalised linear models and presented as means with standard errors stratified by sex and the redefined centres, which were ordered geographically from south to north. These models were adjusted for age (continuous variable) and weighted by season and weekday of the 24-HDR to control for different distributions of participants across seasons and weekdays of the recall. The contribution of each individual compound and class of flavonoids to the total intake was calculated as a percentage according to the two European regions (MED countries: all centres in Greece, Spain, Italy and the south of France; non-MED countries: all centres in the north-east and north-west of France, Germany, the Netherlands, UK general population, Denmark, Sweden and Norway). The contribution of each food group to overall flavonoid intake by European region was also computed as a percentage.

Differences in flavonoid intakes stratified by European region were also compared using general linear models according to the categories of sex, age (35-44, 45-54, $55-64$ or $65-74$ years), BMI $\left(<25,25\right.$ to $<30$ or $\left.\geq 30 \mathrm{~kg} / \mathrm{m}^{2}\right)$, educational level (none, primary completed, technical/ professional, secondary school or university degree), smoking status (never smoker, present smoker or former smoker) and level of physical activity (inactive, moderately inactive, moderately active or active). All these models were adjusted for sex (categorical), age (continuous), centre (categorical), BMI (continuous) and energy intake (continuous) and weighted by season and weekday. $P$ values $<0.05$ (two-tailed) were considered significant. All analyses were conducted using the SPSS Statistics software (version 19.0; SPSS Inc.).

\section{Results}

For both sexes, consumers with the highest total flavonoid intake were from the UK general population (in men $548.8 \mathrm{mg} / \mathrm{d}$ and in women $501.7 \mathrm{mg} / \mathrm{d}$ ). Meanwhile, consumers with the lowest total flavonoid intake were in Greece (in men $250.7 \mathrm{mg} / \mathrm{d}$ and in women $203.6 \mathrm{mg} / \mathrm{d}$; Fig. 1). There was no statistically significant difference in flavonoid intake when adjusted for sex, age, centre, BMI and energy consumption and weighted by season and weekday of 24-HDR between the MED region $(370.2 \mathrm{mg} / \mathrm{d})$ and the nonMED region $(373.7 \mathrm{mg} / \mathrm{d} ; P=0.349$; Table 2$)$. Men had a statistically higher intake of total flavonoids than women in MED countries, while the inverse was found in non-MED countries. Younger people had significantly lower flavonoid consumption than older people in MED and non-MED regions. An inverse trend between $\mathrm{BMI}$ and total flavonoid intake was observed in both regions. According to educational level, participants with technical/professional studies and university graduates had the highest consumption of flavonoids in MED and non-MED countries, respectively. Never and former smokers had the highest flavonoid intakes in both MED and non-MED countries. Physically active participants had the highest intakes, particularly in the MED region.

Table 3 shows the flavonoid class contributors to the total flavonoid intake. Flavanol class was the main contributor in both regions, ranging from 72.5 to $75.0 \%$. More specifically, in MED countries, PA contributed $59.0 \%$ and flavan-3-ol monomers only $13 \cdot 1 \%$, whereas in non-MED region, PA and flavan-3-ol monomers contributed 48.2 and $24.9 \%$ respectively. Flavonols, flavanones and anthocyanidins were intermediate contributors in all regions $(7 \cdot 3-10 \cdot 1 \%)$. Finally, the contributions of flavones and isoflavones were minor $(<1.5 \%)$.

The main food sources of dietary flavonoid intake according to European region are presented in Table 4. In non-MED countries, tea and fruits were the main food items contributing 25.7 and $32.8 \%$ of total flavonoid intake, respectively. Other moderate contributors consisted of wines, juices, cereals, sweets and chocolate products. However, in MED countries, fruits $(55 \cdot 1 \%$, mainly apples and pears), wines (16.7\%), tea $(6 \cdot 8 \%)$ and vegetables $(4.5 \%)$ were the most important food sources.

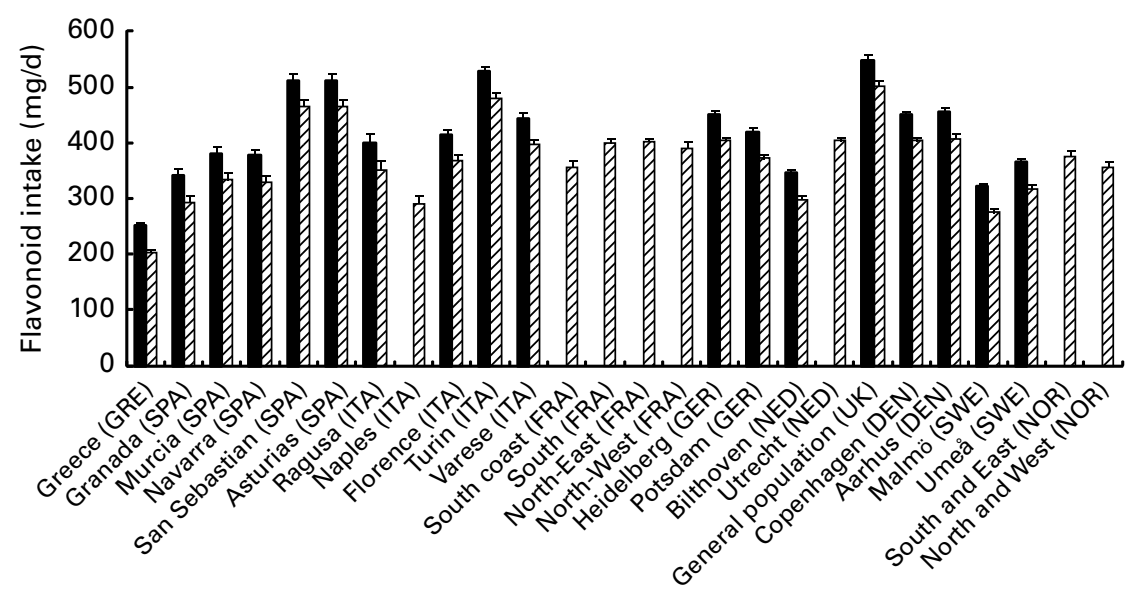

Fig. 1. Adjusted daily flavonoid intake (mg/d), stratified by sex and centre ordered from south to north, adjusted for age and weighted by season and weekday of dietary recall. GRE, Greece; SPA, Spain; ITA, Italy, FRA, France, GER, Germany; NED, The Netherlands; DEN, Denmark; SWE, Sweden; NOR, Norway; $\square$, men; $\boldsymbol{\square}$, women. Values are means, with standard errors represented by vertical bars. 
Table 2. Estimated mean total flavonoid intake ( $\mathrm{mg} / \mathrm{d}$ ) in Mediterranean (MED) and non-MED countries of the European Prospective Investigation into Cancer and Nutrition cohort by socio-demographic and lifestyle factors*

(Mean values with their standard errors)

\begin{tabular}{|c|c|c|c|c|c|c|c|c|c|}
\hline \multirow[b]{2}{*}{ Stratification variable } & \multicolumn{4}{|c|}{ MED countries } & \multicolumn{4}{|c|}{ Non-MED countries } & \multirow[b]{2}{*}{$P \neq$} \\
\hline & $n$ & Mean & SEM & $P \dagger$ & $n$ & Mean & SEM & $P \dagger$ & \\
\hline All & 11285 & $370 \cdot 2$ & 3.0 & & 24443 & 373.7 & $2 \cdot 1$ & & 0.349 \\
\hline Sex & & & & $<0.001$ & & & & $<0.001$ & \\
\hline Men & 4533 & $397 \cdot 7$ & $4 \cdot 8$ & & 8382 & $335 \cdot 8$ & 3.6 & & $<0.001$ \\
\hline Women & 6752 & $356 \cdot 3$ & 3.9 & & 16061 & $400 \cdot 5$ & 2.6 & & $<0.001$ \\
\hline Age (years) & & & & $<0.001$ & & & & $<0.001$ & \\
\hline $35-44$ & 1070 & $314 \cdot 3$ & $9 \cdot 3$ & & 2230 & 341.7 & 6.5 & & 0.014 \\
\hline $45-54$ & 3846 & 349.6 & $5 \cdot 1$ & & 8632 & 368.7 & 3.5 & & 0.002 \\
\hline $55-64$ & 4583 & $409 \cdot 1$ & 4.7 & & 10242 & 387.9 & 3.1 & & $<0.001$ \\
\hline $65-74$ & 1786 & 349.9 & $7 \cdot 7$ & & 3339 & $367 \cdot 2$ & 5.5 & & 0.065 \\
\hline BMI $\left(\mathrm{kg} / \mathrm{m}^{2}\right)$ & & & & $<0.001$ & & & & $<0.001$ & \\
\hline$<25$ & 4037 & $372 \cdot 1$ & $5 \cdot 0$ & & 12596 & 388.5 & 3.0 & & 0.005 \\
\hline 25 to $<30$ & 4804 & $370 \cdot 3$ & 4.5 & & 8895 & 368.0 & 3.4 & & 0.709 \\
\hline$\geq 30$ & 2444 & $348 \cdot 0$ & $6 \cdot 5$ & & 2952 & 338.6 & $5 \cdot 8$ & & 0.244 \\
\hline Level of schooling & & & & $<0.001$ & & & & $<0.001$ & \\
\hline No formal education & 1639 & 338.8 & $8 \cdot 1$ & & 70 & $299 \cdot 1$ & 37.5 & & 0.354 \\
\hline Primary completed & 4360 & $366 \cdot 5$ & 4.9 & & 6109 & 311.2 & $4 \cdot 1$ & & $<0.001$ \\
\hline Technical/professional & 975 & 413.5 & $9 \cdot 8$ & & 7012 & $366 \cdot 6$ & 3.8 & & $<0.001$ \\
\hline Secondary school & 2297 & 384.0 & $6 \cdot 5$ & & 4814 & $387 \cdot 1$ & 4.7 & & 0.586 \\
\hline University degree & 1902 & $357 \cdot 3$ & $7 \cdot 0$ & & 6097 & $432 \cdot 8$ & 4.1 & & $<0.001$ \\
\hline Smoking status & & & & $<0.001$ & & & & $<0.001$ & \\
\hline Never smoker & 5927 & $366 \cdot 7$ & $4 \cdot 2$ & & 11386 & $390 \cdot 1$ & 3.1 & & $<0.001$ \\
\hline Former smoker & 2624 & $406 \cdot 0$ & $6 \cdot 1$ & & 7551 & 389.0 & 3.6 & & 0.010 \\
\hline Present smoker & 2508 & $345 \cdot 3$ & $6 \cdot 2$ & & 5193 & $316 \cdot 6$ & 4.4 & & $<0.001$ \\
\hline Physical activity & & & & $<0.001$ & & & & $<0.001$ & \\
\hline Inactive & 3668 & 338.5 & $5 \cdot 2$ & & 3723 & 354.9 & $5 \cdot 0$ & & 0.020 \\
\hline Moderately inactive & 3956 & 368.7 & 4.8 & & 7889 & $370 \cdot 1$ & 3.4 & & 0.878 \\
\hline Moderately active & 2280 & $392 \cdot 6$ & $6 \cdot 3$ & & 6050 & $380 \cdot 8$ & 3.9 & & 0.110 \\
\hline Active & 1380 & 425.4 & $8 \cdot 0$ & & 4948 & 389.4 & 4.3 & & $<0.001$ \\
\hline
\end{tabular}

*Adjusted for sex, age, centre, energy intake and BMI and weighted by season and weekday of recall. $P$ value is for differences in means.

†Differences between each stratification variable in each region.

$\ddagger$ Differences between MED-countries and non-MED countries.

\section{Discussion}

The present study is the first large descriptive study presenting differences in the total dietary flavonoid intake, the related food sources and socio-demographic and lifestyle determinants between MED and non-MED countries. The results could be readily compared among centres and among regions, because a standardised 24-HDR (EPIC-Soft) and a common flavonoid FCDB were used for the entire EPIC cohort.

In the present study, there was no significant difference in total flavonoid intake between $\operatorname{MED}(370 \cdot 2 \mathrm{mg} / \mathrm{d})$ and nonMED countries $(373.7 \mathrm{mg} / \mathrm{d} ; P<0.349)$, although a large variation in flavonoid intake and food sources was observed among centres. In MED countries, a wide range in total dietary flavonoids was found, ranging from $203.6 \mathrm{mg} / \mathrm{d}$ for Greek women to $527.6 \mathrm{mg} / \mathrm{d}$ for men from Turin (Italy). The highest flavonoid class contributor was by far PA (59.0\%), with its main food sources being fruits, wines and tea ${ }^{(35)}$, as was also reported in an Italian case-control study of gastric cancer $^{(17)}$ and in the Spanish EPIC cohort $^{(19)}$. Greek men and women were the lowest flavonoid consumers in the present study and these findings are consistent with a recent study ${ }^{(18)}$. Furthermore, a south to north gradient of increasing total flavonoids was observed within Spain and Italy, as previously described in the EPIC-Spain cohort ${ }^{(19)}$. This gradient could be due to participants in northern areas of MED countries consuming more apples and pears and red wine than southern areas ${ }^{(42,43)}$.

In non-MED countries, there was also a broad range of flavonoid intakes from $275.7 \mathrm{mg} / \mathrm{d}$ for women from Malmö (Sweden) to $548.8 \mathrm{mg} / \mathrm{d}$ for men of the UK general population. In this region, the main food sources were clearly tea (25.7\%) and fruits (32.8\%) and the major flavonoid class contributors were PA and flavan-3-ol monomers. Countries where tea is widely consumed, such as the UK, The Netherlands, Denmark or Australia will generally have high flavonoid

Table 3. Percentage contribution of classes of total flavonoid intake in the European Prospective Investigation into Cancer and Nutrition cohort $^{\star}$

\begin{tabular}{lcc}
\hline Compound & $\begin{array}{c}\text { MED countries } \\
(\%)\end{array}$ & $\begin{array}{r}\text { Non-MED countries } \\
(\%)\end{array}$ \\
\hline Anthocyanidins & $10 \cdot 1$ & 7.3 \\
Flavonols & 6.7 & 7.9 \\
Flavanones & 9.1 & 8.5 \\
Flavones & 1.5 & 1.1 \\
Flavanols & 72.5 & 75.0 \\
Flavan-3-ol monomers & 13.1 & 24.9 \\
Proanthocyanidins & 59.0 & 48.2 \\
Theaflavins & 0.4 & 1.9 \\
Isoflavones & 0.1 & 0.2 \\
\hline
\end{tabular}

MED, Mediterranean.

${ }^{*}$ Adjusted for age, sex and weighted by season and weekday of dietary recall. 
Table 4. Percentage contributions of food groups and some main foods to the intake of flavonoids by European region*

\begin{tabular}{|c|c|c|}
\hline Food items & MED countries (\%) & Non-MED countries (\%) \\
\hline Potatoes and other tubers & 0.1 & 0.2 \\
\hline Vegetables & 4.5 & $2 \cdot 1$ \\
\hline Leafy vegetables & 1.8 & 0.6 \\
\hline Fruiting vegetables & 0.8 & 0.3 \\
\hline Root vegetables & 0.1 & 0.2 \\
\hline Cabbages & 0.1 & 0.2 \\
\hline Grain and pod vegetables & 0.4 & 0.1 \\
\hline Onion, garlic & 0.9 & 0.5 \\
\hline Other vegetables & 0.3 & 0.2 \\
\hline Legumes & 1.4 & $0 . \overline{5}$ \\
\hline Fruits & $55 \cdot 1$ & $32 \cdot 8$ \\
\hline Citrus fruit & $7 \cdot 0$ & 3.7 \\
\hline Apples and pears & $25 \cdot 9$ & $17 \cdot 2$ \\
\hline Grapes & $5 \cdot 6$ & $2 \cdot 6$ \\
\hline Stone fruits & $11 \cdot 7$ & 4.0 \\
\hline Berries & 2.9 & 3.5 \\
\hline Kiwi & 0.2 & 0.1 \\
\hline Other fruits & 1.9 & 1.7 \\
\hline Nuts and seeds & 0.7 & 0.4 \\
\hline Dairy products & 0.5 & 1.1 \\
\hline Cereals, cakes, biscuits and sweets & 3.7 & $6 \cdot 1$ \\
\hline Chocolate products & 3.6 & 4.4 \\
\hline Non-alcoholic beverages & $9 \cdot 4$ & $35 \cdot 3$ \\
\hline Tea & $6 \cdot 8$ & $25 \cdot 7$ \\
\hline Fruit and vegetable juices & $2 \cdot 4$ & $7 \cdot 1$ \\
\hline Other non-alcoholic beverages & 0.2 & 2.5 \\
\hline Alcoholic beverages & $19 \cdot 4$ & $13 \cdot 0$ \\
\hline Wines & $16 \cdot 7$ & $9 \cdot 8$ \\
\hline Beer and cider & $2 \cdot 6$ & $2 \cdot 6$ \\
\hline Other alcoholic beverages & 0.1 & 0.5 \\
\hline Condiments and sauces & 0.7 & 0.6 \\
\hline Soups, bouillons & 0.7 & 3.2 \\
\hline Soya products & 0.1 & $0 \cdot 1$ \\
\hline Meat, fish and eggs & 0.0 & 0.0 \\
\hline Fat and oils & 0.0 & 0.0 \\
\hline
\end{tabular}

intake, as a result of the sum of flavan-3-ol monomers and flavanol-derived compounds (theaflavins and thearubigins), the latter being the highest contributing class ${ }^{(21-24)}$. However, in the present study, thearubigins were not included because they were obtained by an unsuitable method ${ }^{(7)}$. Excluding thearubigins from the analysis, PA became the major flavonoid contributor in the non-MED region, especially in countries where tea consumption is less prevalent, for instance, in our Scandinavian centres (data not shown) or in a recent Finnish study. ${ }^{(16)}$.

Differences between MED and non-MED countries were also explained by some socio-demographic, anthropometric and lifestyle factors. With respect to sex, men had a higher flavonoid intake than women in MED countries as men tend to drink more wine, particularly red wine ${ }^{(19)}$. However, in nonMED countries, the opposite was found, as women tended to consume more tea than men ${ }^{(44)}$. Flavonoid intake was also shown to increase with age in both these regions ${ }^{(19,44)}$. Again, the observed differences were largely due to variations in wine and tea consumption. A US study ${ }^{(14)}$ showed that flavonoid intake increased up to the age group of 51-70 years, but in the age group $>70$ years, the consumption decreased significantly. In the present study, this reduction was also clearly detected in the oldest age group (65-74 years). Also, in the present study, participants living in the non-MED region and having a BMI of less than $25 \mathrm{~kg} / \mathrm{m}^{2}$ had a significantly higher flavonoid consumption than those in any other BMI groups. In the MED countries, no statistical difference was observed between normal and overweight participants and flavonoid intake. However, in a previous analysis from the EPIC-Spain cohort, overweight people had the highest flavonoid intake; the difference was small but statistically significant ${ }^{(19)}$. In the non-MED region, less-educated adults had the lowest flavonoid intake, while people with a university degree had the highest; thus, flavonoid intake seems to increase with higher educational level. In contrast, in an US study, flavonoid intake was higher among those with a higher poverty income ratio ${ }^{(14)}$. People with a higher education and/or income are usually more conscious of good nutrition and health, so they may take more care of themselves and consume more healthy foods such as fresh fruit and vegetables ${ }^{(45,46)}$. However, in MED countries, the highest flavonoid intake was observed in the subjects of technical/ professional education, who also tended to have the highest wine intakes ${ }^{(47)}$. Never and former smokers had a higher flavonoid intake than present smokers in both MED and 
non-MED countries, as was observed previously in the EPICSpain cohort ${ }^{(19)}$. However, smoking status was not associated with flavonoid intake in the USA ${ }^{(14)}$. In both regions, the trend of increasing flavonoid intake with more physical activity was probably observed because physically active people generally consume more fruits and vegetables, as shown in the EPIC-Spain cohort ${ }^{(48)}$.

Since the in vitro evidence on health effects of flavonoids was published ${ }^{(10,11)}$, some epidemiological studies have reported inverse associations between flavonoid intake and chronic diseases such as $\mathrm{CVD}^{(49)}$ and some cancers ${ }^{(17,50-53)}$. Despite the comparable flavonoid intakes between MED and non-MED countries in the present study, there is a well-established south to north gradient of CVD mortality ${ }^{(54)}$. This might be explained in part by the different consumption patterns of flavonoid classes and their food sources, as observed in the present study. In addition, other established dietary and lifestyle risk factors of CVD are more prevalent in non-MED countries $^{(5,55,56)}$. Further basic and epidemiological studies are needed to clarify the potential role of flavonoids against CVD and other chronic diseases.

The present study has a number of relevant strengths. The first is the large number of participants in the EPIC calibration subcohort. The second is the complete list of flavonoids used. The third strength is the use of the most updated and relatively large FCDB on worldwide analytical flavonoid data, which was expanded with plant-plant estimations, thus obtaining a final database with 1877 food items with only $10 \%$ of unknown values. The fourth stems from the collection of dietary data using a standardised 24-HDR in the whole cohort ${ }^{(57)}$; thus, the results are easily comparable across the countries. Nevertheless, some limitations were encountered. As not all the EPIC cohorts are population based, these findings cannot be extrapolated to the general population of each region $^{(28)}$. A relevant weakness is the likely underestimation of real flavonoid intake, due to the unknown food flavonoid composition data (10\% of data in our FCDB and thearubigin data), and the omission of some food items (such as coffee substitutes) and herb/plant supplement intakes in the present analysis (which are up to $5 \%$ of the population in Denmark, the highest supplement consuming country) ${ }^{(58)}$. Another limitation is the use of a single 24-HDR, which is less likely to reflect true usual individual diet. However, analyses were weighted by season and weekday of dietary recall and 24-HDR is a useful method to describe the average dietary intake of a group, particularly when estimated from a large number of subjects ${ }^{(59)}$.

In summary, the data obtained in the present study show total flavonoid intake among the twenty-six EPIC participating centres in ten European countries. We also describe the major dietary flavonoid class contributors and the main food sources that differentiated the MED and non-MED regions. There was no significant difference in total flavonoid intake between MED and non-MED countries, although there were differences in flavonoid classes and their food sources between both regions. Significant socio-demographic and lifestyle factors related to total flavonoid intakes were also highlighted by European region. These descriptive data should be of value in the future as a first step in dietary flavonoid assessment and their potential role in health and disease.

\section{Acknowledgements}

The authors declare no conflict of interest. The present work was carried out with the financial support of the European Commission: Public Health and Consumer Protection Directorate 1993 to 2004; Research Directorate-General 2005; Ligue contre le Cancer, Institut Gustave Roussy, Mutuelle Générale de l'Education Nationale, Institut National de la Santé et de la Recherche Médicale (INSERM) (France); German Cancer Aid; German Cancer Research Center; German Federal Ministry of Education and Research; Danish Cancer Society; the Spanish Ministry of Health (ISCIII RETICC RD06/0020); Spanish Regional Governments of Andalusia, Asturias, Basque Country, Murcia (No. 6236) and Navarra and the Catalan Institute of Oncology; Cancer Research UK; Medical Research Council, UK; the Stroke Association, UK; British Heart Foundation; Department of Health, UK; Food Standards Agency, UK; the Wellcome Trust, UK; the Hellenic Health Foundation and the Stavros Niarchos Foundation; Italian Association for Research on Cancer; Compagnia San Paolo, Italy; Dutch Ministry of Public Health, Welfare and Sports; Dutch Ministry of Health; Dutch Prevention Funds; LK Research Funds; Dutch ZON (Zorg Onderzoek Nederland); World Cancer Research Fund (WCRF); Statistics Netherlands (The Netherlands); Swedish Cancer Society; Swedish Scientific Council; Regional Government of Skane, Sweden; Nordforsk - Center of Excellence Programme; some authors are partners of Environmental Cancer Risk, Nutrition and Individual Susceptibility (ECNIS), a network of excellence of the 6th Framework Programme of the European Commission. R. Z.-R. is thankful for a postdoctoral 'Sara Borrell' programme (CD09/00133) from the MEC and Instituto de Salud Carlos III. The author contributions are as follows: R. Z.-R. and C. A. G. designed the research; R. Z.-R. and V. K. conducted the research; R. Z.-R. and L. L.-B. performed the statistical analysis; R. Z.-R. wrote the manuscript. All authors read, critically reviewed and approved the final manuscript.

\section{References}

1. Trichopoulou A, Costacou T, Bamia C, et al. (2003) Adherence to a Mediterranean diet and survival in a Greek population. $N$ Engl J Med 348, 2599-2608.

2. Estruch R, Martínez-González MA, Corella D, et al. (2006) Effects of a Mediterranean-style diet on cardiovascular risk factors: a randomized trial. Ann Intern Med 145, 1-11.

3. Sofi F, Cesari F, Abbate R, et al. (2008) Adherence to Mediterranean diet and health status: meta-analysis. BMJ 337, a1344.

4. Buckland G, Agudo A, Lujan L, et al. (2010) Adherence to a Mediterranean diet and risk of gastric adenocarcinoma within the European Prospective Investigation into Cancer and Nutrition (EPIC) cohort study. Am J Clin Nutr 91, $381-390$

5. Martinez-Gonzalez MA, Bes-Rastrollo M, Serra-Majem L, et al (2009) Mediterranean food pattern and the primary prevention of chronic disease: recent developments. Nutr Rev $\mathbf{6 7}$, Suppl. 1, S111-S116. 
6. Neveu V, Perez-Jimenez J, Vos F, et al. (2010) Phenol-Explorer: an online comprehensive database on polyphenol contents in foods. Database (Oxford) 2010, bap024.

7. US Departament of Agriculture (2007) USDA Database for the Flavonoid Content of Selected Foods, Release 2.1 ed. Beltsville, MD: USDA.

8. Manach C, Scalbert A, Morand C, et al. (2004) Polyphenols: food sources and bioavailability. Am J Clin Nutr 79, 727-747.

9. Manach C, Williamson G, Morand C, et al. (2005) Bioavailability and bioefficacy of polyphenols in humans. I. Review of 97 bioavailability studies. Am J Clin Nutr 81, 230S-242S.

10. Cazarolli LH, Zanatta L, Alberton EH, et al. (2008) Flavonoids: prospective drug candidates. Mini Rev Med Chem $\mathbf{8}$, 1429-1440.

11. Yao LH, Jiang YM, Shi J, et al. (2004) Flavonoids in food and their health benefits. Plant Foods Hum Nutr 59, 113-122.

12. Arts IC \& Hollman PC (2005) Polyphenols and disease risk in epidemiologic studies. Am J Clin Nutr 81, 317S-325S.

13. Knekt P, Kumpulainen J, Jarvinen R, et al. (2002) Flavonoid intake and risk of chronic diseases. Am J Clin Nutr $\mathbf{7 6}$, $560-568$.

14. Chun OK, Chung SJ \& Song WO (2007) Estimated dietary flavonoid intake and major food sources of US adults. J Nutr 137, 1244-1252.

15. Wang Y, Chung SJ, Song WO, et al. (2011) Estimation of daily proanthocyanidin intake and major food sources in the U.S. diet. J Nutr 141, 447-452.

16. Ovaskainen ML, Torronen R, Koponen JM, et al. (2008) Dietary intake and major food sources of polyphenols in Finnish adults. $J$ Nutr 138, 562-566.

17. Rossi M, Rosato V, Bosetti C, et al. (2010) Flavonoids, proanthocyanidins, and the risk of stomach cancer. Cancer Causes Control 21, 1597-1604.

18. Dilis V \& Trichopoulou A (2010) Antioxidant intakes and food sources in Greek adults. J Nutr 140, 1274-1279.

19. Zamora-Ros R, Andres-Lacueva C, Lamuela-Raventos RM, et al. (2010) Estimation of dietary sources and flavonoid intake in a Spanish adult population (EPIC-Spain). $J \mathrm{Am}$ Diet Assoc 110, 390-398.

20. Perez-Jimenez J, Fezeu L, Touvier M, et al. (2011) Dietary intake of 337 polyphenols in French adults. Am J Clin Nutr 93, $1220-1228$.

21. Johannot L \& Somerset SM (2006) Age-related variations in flavonoid intake and sources in the Australian population. Public Health Nutr 9, 1045-1054.

22. Justesen U, Knuthsen P \& Leth T (1997) Determination of plant polyphenols in Danish foodstuffs by HPLC-UV and LC-MS detection. Cancer Lett 114, 165-167.

23. Arts IC, Hollman PC, Feskens EJ, et al. (2001) Catechin intake might explain the inverse relation between tea consumption and ischemic heart disease: the Zutphen Elderly Study. Am J Clin Nutr 74, 227-232.

24. Hertog MG, Hollman PC, Katan MB, et al. (1993) Intake of potentially anticarcinogenic flavonoids and their determinants in adults in The Netherlands. Nutr Cancer 20, 21-29.

25. Riboli E \& Kaaks R (1997) The EPIC Project: rationale and study design. European Prospective Investigation into Cancer and Nutrition. Int J Epidemiol 26, Suppl. 1, S6-14.

26. Riboli E, Hunt KJ, Slimani N, et al. (2002) European Prospective Investigation into Cancer and Nutrition (EPIC): study populations and data collection. Public Health Nutr 5, 1113-1124.

27. Slimani N, Kaaks R, Ferrari P, et al. (2002) European Prospective Investigation into Cancer and Nutrition (EPIC) calibration study: rationale, design and population characteristics. Public Health Nutr 5, 1125-1145.

28. Slimani N, Fahey M, Welch AA, et al. (2002) Diversity of dietary patterns observed in the European Prospective Investigation into Cancer and Nutrition (EPIC) project. Public Health Nutr 5, 1311-1328.

29. Slimani N, Deharveng G, Charrondiere RU, et al. (1999) Structure of the standardized computerized 24-h diet recall interview used as reference method in the 22 centers participating in the EPIC project. European Prospective Investigation into Cancer and Nutrition. Comput Methods Programs Biomed 58, 251-266.

30. Slimani N, Ferrari P, Ocke M, et al. (2000) Standardization of the 24-hour diet recall calibration method used in the European Prospective Investigation into Cancer and Nutrition (EPIC): general concepts and preliminary results. Eur $J$ Clin Nutr 54, 900-917.

31. Brustad M, Skeie G, Braaten T, et al. (2003) Comparison of telephone vs face-to-face interviews in the assessment of dietary intake by the $24 \mathrm{~h}$ recall EPIC SOFT program - the Norwegian calibration study. Eur J Clin Nutr 57, 107-113.

32. Wareham NJ, Jakes RW, Rennie KL, et al. (2003) Validity and repeatability of a simple index derived from the short physical activity questionnaire used in the European Prospective Investigation into Cancer and Nutrition (EPIC) study. Public Health Nutr 6, 407-413.

33. Zamora-Ros R, Knaze V, Luján-Barroso L, et al. (2011) Estimation of the intake of anthocyanidins and their food sources in the European Prospective Investigation in to Cancer and Nutrition (EPIC) study. Br J Nutr 106, 1090-1099.

34. Zamora-Ros R, Knaze V, Luján-Barroso L, et al. (2011) Estimated dietary intakes of flavonols, flavanones and flavones in the European Prospective Investigation into Cancer and Nutrition (EPIC) 24-h dietary recall cohort. Br J Nutr 106, $1915-1925$.

35. Knaze V, Zamora-Ros R, Luján-Barroso L, et al. (2012) Intake estimation of total and individual flavan-3-ols, proanthocyanidins and theaflavins, their food sources and determinants in the European Prospective Investigation into Cancer and Nutrition (EPIC) study. Br J Nutr 108, 1095-1108.

36. Zamora-Ros R, Knaze V, Luján-Barroso L, et al. (2012) Dietary intakes and food sources of phytoestrogens in the European Prospective Investigation into Cancer and Nutrition (EPIC) 24-hour dietary recall cohort. Eur J Clin Nutr 66, 932-941.

37. US Departament of Agriculture (2008) USDA Database for the Isoflavone Content of Selected Foods, Release 2.0 ed. Beltsville, MD: USDA.

38. US Departament of Agriculture (2004) USDA Database for the Proanthocyanidin Content of Selected Foods. Beltsville, MD: USDA

39. Ward HA, Kuhnle GG, Mulligan AA, et al. (2010) Breast, colorectal, and prostate cancer risk in the European Prospective Investigation into Cancer and Nutrition-Norfolk in relation to phytoestrogen intake derived from an improved database. Am J Clin Nutr 91, 440-448.

40. Crozier A, Lean MEJ, McDonald MS, et al. (1997) Quantitative analysis of the flavonoid content of commercial tomatoes, onions, lettuces, and celery. J Agric Food Chem 45, 590-595.

41. Horn-Ross PL, Barnes S, Lee M, et al. (2000) Assessing phytoestrogen exposure in epidemiologic studies: development of a database (United States). Cancer Causes Control 11, 289-298.

42. Agudo A, Slimani N, Ocke MC, et al. (2002) Consumption of vegetables, fruit and other plant foods in the European 
Prospective Investigation into Cancer and Nutrition (EPIC) cohorts from 10 European countries. Public Health Nutr $\mathbf{5}$, $1179-1196$

43. Sieri S, Agudo A, Kesse E, et al. (2002) Patterns of alcohol consumption in 10 European countries participating in the European Prospective Investigation into Cancer and Nutrition (EPIC) project. Public Health Nutr 5, 1287-1296.

44. Arts IC, Hollman PC, Feskens EJ, et al. (2001) Catechin intake and associated dietary and lifestyle factors in a representative sample of Dutch men and women. Eur J Clin Nutr 55, $76-81$.

45. James WP, Nelson M, Ralph A, et al. (1997) Socioeconomic determinants of health. The contribution of nutrition to inequalities in health. BMJ 314, 1545-1549.

46. Schroder H, Marrugat J \& Covas MI (2006) High monetary costs of dietary patterns associated with lower body mass index: a population-based study. Int J Obes (Lond) 30, $1574-1579$

47. Marques-Vidal P \& Dias CM (2005) Trends and determinants of alcohol consumption in Portugal: results from the national health surveys 1995 to 1996 and 1998 to 1999. Alcohol Clin Exp Res 29, 89-97.

48. Agudo A \& Pera G (1999) Vegetable and fruit consumption associated with anthropometric, dietary and lifestyle factors in Spain. EPIC Group of Spain. European Prospective Investigation into Cancer. Public Health Nutr 2, 263-271.

49. Hooper L, Kroon PA, Rimm EB, et al. (2008) Flavonoids, flavonoid-rich foods, and cardiovascular risk: a meta-analysis of randomized controlled trials. Am J Clin Nutr 88, 38-50.

50. Arts IC, Jacobs DR Jr, Gross M, et al. (2002) Dietary catechins and cancer incidence among postmenopausal women: the Iowa Women's Health Study (United States). Cancer Causes Control 13, 373-382.
51. Lagiou P, Rossi M, Lagiou A, et al. (2008) Flavonoid intake and liver cancer: a case-control study in Greece. Cancer Causes Control 19, 813-818.

52. Nothlings U, Murphy SP, Wilkens LR, et al. (2007) Flavonols and pancreatic cancer risk: the multiethnic cohort study. $\mathrm{Am}$ J Epidemiol 166, 924-931.

53. Rossi M, Negri E, Talamini R, et al. (2006) Flavonoids and colorectal cancer in Italy. Cancer Epidemiol Biomarkers Prev 15, 1555-1558

54. Levi F, Lucchini F, Negri E, et al. (2002) Trends in mortality from cardiovascular and cerebrovascular diseases in Europe and other areas of the world. Heart 88, 119-124.

55. Jakes RW, Day NE, Khaw KT, et al. (2003) Television viewing and low participation in vigorous recreation are independently associated with obesity and markers of cardiovascular disease risk: EPIC-Norfolk population-based study. Eur J Clin Nutr 57, 1089-1096.

56. Linseisen J, Welch AA, Ocke M, et al. (2009) Dietary fat intake in the European Prospective Investigation into Cancer and Nutrition: results from the 24-h dietary recalls. Eur J Clin Nutr 63, Suppl. 4, S61-S80.

57. Slimani N \& Valsta L (2002) Perspectives of using the EPICSOFT programme in the context of pan-European nutritional monitoring surveys: methodological and practical implications. Eur J Clin Nutr 56, Suppl. 2, S63-S74.

58. Skeie G, Braaten T, Hjartaker A, et al. (2009) Use of dietary supplements in the European Prospective Investigation into Cancer and Nutrition calibration study. Eur J Clin Nutr 63, Suppl. 5, S226-S238.

59. Willet W (1998) Nutritional Epidemiology, 2nd ed. New York: Oxford University Press. 